\title{
Bacterial Pathogens of Surgical Site Infections in Cancer Patients at a Tertiary Regional Cancer Centre, South India
}

\author{
B.G. Sumathi* \\ Department of Microbiology, Kidwai Memorial Institute of Oncology, Bangalore 5600 29, India \\ *Corresponding author
}

\section{A B S T R A C T}

\section{Keywords}

Cancer, Bacterial

Surgical Site

Infections, Solid

tumors, Resistance,

Gram Negative

Bacilli, Gram positive Cocci.

\begin{tabular}{l}
\hline Article Info \\
\hline Accepted: \\
20 September 2016 \\
Available Online: \\
10 October 2016
\end{tabular}

A retrospective microbiological study of surgical site infections(SSIs) from oncological departments of Surgery, Gynaecology, Head and Neck and Oral oncology was evaluated to estimate the percentage resistance pattern of gram negative and gram positive bacteria from cancer patients. Surgical site infections are the nodal sites and direct index factor for the assessment of health-care associated infections in a hospital with a potential high risk for cancer patients. A total of 1546 post operative infected wound discharges and post operative drains insitu discharges from surgical oncology departments were analysed between 2012 to 2014 for bacterial infections. Bacterial isolation was done by conventional laboratory methods in the department of microbiology. Susceptibility and resistance pattern to isolated pathogens were done by the conventional Stokes' method of antibiotic testing and extended-spectrum betalactamases(ESBL) were estimated by conventional 3 disc synergy diffusion method. Anaerobic infections were not included in the study. One thousand five hundred and forty six post operative infected wound and discharges from drains in-situ were analysed which yielded polymicrobial and monomicrobial infections. Out of 1058 samples the predominant isolates was gram negative bacilli followed by gram positive cocci with 488 samples. The predominant pathogens were E.coli 632(59.73\%);Klebsiella species148 (13.98\%); Pseudomonas species 110(10.39\%);Non fermenting gram negative bacilli 86(8.12\%);Proteus species and Morganella morgani 62(5.86\%); Citrobacter species20(1.89\%) and Enterococci species262(53.68\%); Staphylococcus aureus 202(41.3\%); Methicillin Resistant Staphylococcus aureus 14(2.86\%);Coagulase Negative Staphylococcus(CONS)8(1.6\%); and $\beta$ streptococci 2(.2\%). Extended spectrum beta-lactamases production out of the total 1058 samples were E.coli 328 (31.00\%); Klebsiella species32(3.02\%); Non fermenting gram negative bacilli16(1.51\%); Proteus species $12(1.13 \%)$; Pseudomonas species 6(0.56\%) Citrobacter species 6(0.56\%).Amongst the total gram negative bacilli(1058), SSI surgical oncology services had the maximum SSIs isolates $48.39 \%$; followed by departments of gynaec oncology $20.79 \%$; head and neck oncology $6.61 \%$; oral oncology $1.70 \%$. Among the gram positive cocci(488) surgical oncology department had the maximum isolates $40.98 \%$; followed by gynaec oncology $31.14 \%$; head and neck oncology $4.91 \%$; oral oncology $1.63 \%$. Poymicrobial infection isolates was 516(33.37\%) and monomicrobial isolates was $386(24.96 \%)$. Bacterial surgical site infections is the complication of surgery. The spectrum of post operative oncological surgical site infections in a cancer hospital are a nidus for healthcare associated infections and increased health care burden. Relevant oncological surgical risk factors and antibiotic therapy need be evaluated in high risk patients like cancer to avoid early mortality and morbidity. This is the first study on surgical site bacterial infections in cancer patients in our hospital, Kidwai Memorial Institute of Oncology, a regional cancer centre in South India. 


\section{Introduction}

Surgical-site infection (SSI) is defined as infections that occur within 30 days of a surgical procedure (or within 1 year, if an implant has been left in place) affecting either the incision or deep tissue at the operative site (Horan et al., 1992; Mangram et al., 1999).

The National Nosocomial Infection System (NNIS) of the US Centers for Disease Control and Prevention, modified the definition of surgical wound infection by introducing the concept of surgical site infection, divided into wound infection and organ/space infection. In an attempt to compare the prevalence of SSI between hospitals, the NNIS developed an SSI risk index based on the American Society of Anesthesiologists score, the degree of contamination of the wound, and duration of the operation (Horan et al., 1992; Mangram et al., 1999).

BSSI's are the point source for hospital infection and SSIs are associated with increase in hospital stay and thereby increase health care costs and morbidity/lethality (Paulo et al., 2011), delay in rehabilitation, post operative adjuvant therapy which in turn may affect the overall prognosis (Jelena Sotirović et al., 2015).

Patients with solid tumors frequently undergo various diagnostic and therapeutic surgical procedures and surgical site infections (SSIs) are more common in these patients in contrast to haematologic malignant patients (Sutton, 2014).

Procedure such as surgical interventions, tracheostomies, biopsies, bone marrow aspirations, endoscopy, and indwelling vascular and urinary catheters break the natural protective barrier between the internal environment and/ external environment and allow entry of microorganisms and predispose to infection (Teresa, 2014). Presence of BSSI's in cancer with added presence of ESBLs give rise to multiply drug resistance which in turn reflect on the hospital health care system. SSI is a multifactorial condition and the risk factors involved in its onset are common for most surgeries like age, obesity and surgical time as from studies reported. Ashley et al., in their study mention that the passage of bacteria through surgical drapes is a potential cause of wound infection which easily penetrate all woven re-usable fabrics within $30 \mathrm{~min}$ and recommend the use of non-woven disposable drapes or woven drapes with an impermeable operating tray in all surgical cases. SSI's vary with the source of primary solid tumors. Intra abdominal cancer patients require aggressive surgical intervention for proper diagnosis, staging, and cure and which in turn carry a high incidence of surgical site infections (Meuid et al., 1988) and surgery for abdominal cancer is associated with a higher degree of morbidity and mortality than other standard procedures (Peter, 2003).

Rectal cancer operations are at a greater risk of SSI due to procedures as creation of ostomies, and total excision of the mesorectum with anastomoses close to the anal margin thereby lengthening surgical time and increase the likelihood of bacterial contamination (Tsuyoshi et al., 2006; Law et al., 2004).

Longer duration of hospital stay is the common factor for oncological SSIs as reported by studies.

Methicillin Resistant Staphylococci aureus (MRSA) another important drug resistant gram positive pathogens detrimental for SSIs need to be ruled out which may lead to 
persistance of SSIs and nosocomial infection. SSI infections may present as monomicrobial or polymicrobial in high risk cancer patients.

Polymicrobial infections have precedence over monomicrobial infections and have doubled in frequency in recent years in cancer patients (Jeffrey et al., 2003) and are predominantly tissue-based infections with associated greater morbidity and mortality than monomicrobial infections. Eighty percent of polymicrobial infections are gram-negative and $33 \%$ are caused exclusively by multiple species of gramnegative bacilli (Elting et al., 1986). In the milieu of poly or monomicrobial infections presence of extended-spectrum betalactamases add to the delay in reducing SSIs within the first 72 hours due to tissue stress and related surgical risk factors. Presence of ESBL's may imply an additional therapeutic difficulties to treat cancer patients and be detected as a routine test to avoid multiply drug resistance and prevent avoidable surgical risk factors. Antibiotic pressure in high risk subjects may give rise to more ESBL,s and directly relate to health care associated infections.

Montes et al., (2014) in their study of 173 SSI for ESBL's in cancer patients report that appropriate timing and duration of perioperative antimicrobial prophylaxis will lower the risk of ESBL's. Antibiotic prophylaxis guidelines and reduced exposure to cephalosporins may also potentially decrease the risk of ESBL and SSI's. The incidence of SSIs may be as high as $20 \%$, depending on the surgical procedure, the surveillance criteria used, and the quality of data collection. In many SSIs, the responsible pathogens originate from the patient's endogenous flora (Owens et al., 2008) and the causative pathogens related to the type of surgery; where the most commonly isolated organisms are $S$. aureus, coagulase-negative staphylococci,

Enterococcus spp. and E. coli.

The Centers for Disease Control and Prevention guidelines for the prevention of SSIs emphasise the importance of good patient preparation, aseptic practice, and attention to surgical technique; antimicrobial prophylaxis is also indicated in specific circumstances. Newer technologies as the microbial sealants, offer the ability to seal and immobilise skin flora for the duration of a surgical procedure; a strong case therefore exists for evaluating such technologies and implementing them into routine clinical practice as appropriate (Owens et al., 2008).

Educating about hand hygiene, appropriate and timely use of antibiotics, careful insertion and monitoring of catheters, good asepsis and preventive measures during surgery can reduce the incidence of SSIs in oncology patients. Studies mention that half or more of SSIs are due to instrumentation and surgical intervention including pre, peri and post operatively. SSIs form a direct index to health-care associated infections and therefore a thorough evaluation of oncological surgical risk factors prior to onco surgeries may reduce health care burden in terms of period or length of hospital stay, cost and reduction in morbidity and mortality.

\section{Subjects and Methods}

A total of 1058 samples from cancer patients with surgical site infections which included post-operative site discharges and postoperative site drain discharges between 2012 and 2014 were received from oncological services of Surgery, Head and Neck, Oral, Gynaecology to the department of microbiology. Culture positive isolates were considered for analysis of bacterial infections and were identified by 
conventional methods (Medical Microbiology, 1996). Culture negative samples, isolation of anaerobic infections, colonisers and contaminants were not included in our study. Patients with previous chemotherapy and/or radiotherapy were excluded in the study.

\section{Antimicrobial Susceptibility Testing}

The susceptibilities to antimicrobial agents were determined by Stokes' disc diffusion method using Amikacin (30mcg); Gentamicin (10mcg); Cefotaxime $(30 \mathrm{mcg})$; Ceftazidime (30mcg); Cefuroxime $(30 \mathrm{mcg}$ ); Ciprofloxacin (5mcg); Cefaperazone (75mcg); Imipenem $(10 \mathrm{mcg}) \quad$ Pipercillin/ Tazobactum (100/10mcg); and simultaneous screening tests for ESBL's by CLSI disc diffusion method and phenotypic confirmation test by disc potentiation test with ceftazidime $(30 \mathrm{mcg})$ and cefotaxime (30 mcg) and amoxicillin-clavulanic acid discs $30 \mathrm{mcg}(20 / 10 \mathrm{mcg}$ ); (all commercially available discs, Hi-media, India) as recommended by the Clinical and Laboratory Standards Institute(CLSI) guidelines.

Screening for Methicillin Resistant Staphylococcus aureus(MRSA) was done by Stokes' disc diffusion method using

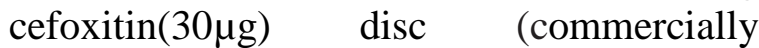
available discs, Hi-media, India). The antibiotic disc susceptibility testing is done based on the antibiotics advocated routinely to cancer patients in our hospital.

\section{Results and Discussion}

One thousand five hundred and fifty eight BSSI samples of cancer patients yielded predominantly polymicrobial, less monomicrobial infection and ESBL's.

E.coli 632(59.73\%); Klebsiella species 148 (13.98\%); Pseudomonas species 110 (10.39\%); Non fermenting gram negative bacilli 86(8.12\%); Proteus species 62 (5.86\%); Citrobacter species 20(1.89\%) and out of the gram positive pathogens Enterococci species $262 \quad(53.68 \%)$; Staphylococcus aureus 202(41.3\%); Methicillin Resistant Staphylococcus aureus (MRSA) 14(2.86\%); Coagulase Negative Staphylococcus (CONS) 8;(1.6\%); and $\beta$ streptococci $2(.2 \%)$ were predominant isolates from our study Table 1 and Table 2. CONS was considered as pathogen after repeat isolation from the BSSI. There were 4 vancomycin and 6 rifampicin resistant isolates of S.aureus however we did not have vancomycin resistant Enterococci. Our study correlates to the study of Jelena Sotirović et al., (2015).

In their study by Diana Vilar-Compte et al., bacteria most frequently isolated were $E$. coli, Pseudomonas sp S.aureus, and coagulase-negative Staphylococcus.

Extended-spectrum beta-lactamases (ESBL) production out of the total 1058 samples were E.coli 328(31.00\%); Klebsiella species $32(3.02 \%)$; Non fermenting gram negative bacilli1 6 (1.51\%); Proteus species 12 (1.13\%); Pseudomonas aeruginosa 6 $(0.56 \%)$ Citrobacter species 6(0.56\%).

Overall ESBL was $37.80 \%$ (400/1058) with Escherichia coli (E.coli) being the highest ESBL producer.

Amongst the oncological services, the total gram negative bacilli was(1058), BSSI from surgical oncology department had the maximum isolates 48.39\%; followed by departments of gynaec oncology 20.79\%; head and neck oncology 6.61\%; oral oncology $1.70 \%$. Among the gram positive cocci (488) oncosurgery department had the maximum isolates $40.98 \%$; followed by gynaec oncology $31.14 \%$; head and neck oncology $4.91 \%$; oral oncology $1.63 \%$. 
Polymicrobial infection isolates was $516(33.37 \%)$ and monomicrobial isolates was $386(24.96 \%)$.

The maximum resistance of the gram negative bacilli was to cefataxime and to ceftazidime and gram positive cocci to erythromycin and gentamicin from our studies as in table 3 and table 4.

This is the first study on bacterial BSSIs in cancer patients reported from a referral regional cancer centre in South India. Our analyses shows a moderate BSSIs in cancer patients. Surgical site infection rate in non cancer patients in India vary from a low of $2.5 \%$ to a high of $41.9 \%$ over a period of decades (DianaVilar-Compte et al., 2000). Cancer patients are classified as being at high risk for hospital acquired infections and becomes pertinant to identify risk factors for possible outbreaks in hospitalized cancer patients.

The microbiological pathogens of BSSIs in cancer patients from our study were predominantly from the alimentary tract very similar to the report of Nikolaos et al., (2015) where the prominent pathogens in neutropenic hosts were from the alimentary tract.

Cancer or high risk patients are more susceptible than non cancer patients to hospital acquired infection due to underlying immunocompromised state, surgery, use of invasive technology (ie, catheters/drains insitu) and environmental factors. Velasco Thuler et al., (2005) found that the median infection rate was much higher in the oncology intensive care unit than in the non oncology intensive care unit. Ananya et al., (1997) mention that the cardinal feature and independent risk factor in oncological surgeries is if the operative time duration longer than 2 hours. Data study from 611 patients done by Serra-Aracil $\mathrm{X}$ et al.,
(Anaya et al., 2012) where 383 patients underwent surgery for colon cancer and 228 underwent surgery for rectal cancer, surgical site infection was observed in $89(23.2 \%)$ colon cancer patients and in $63(27.6 \%)$ rectal cancer patients. The prevalence of SSI in elective colon and rectal operations remains high despite the application of evidence-based preventive measures while in women undergoing surgery for gynecologic cancer are associated with longer mean hospital stay and higher rate of resurgery, sepsis, and wound dehiscence in a study by Mahdi et al., (2011).

Risk factors for BSSIs are pre, peri and post surgery depending on the type of organ involved in cancer surgery. Common predictive risk factors are contaminated and infected operations, surgical duration greater than 280 minutes, male sex, prior radiotherapy, American Society of Anesthesiology class III to V, and antimicrobial prophylaxis not according to protocol. E. coli, Klebsiella species,non fermenting gram negative bacilli and proteus species were the main gram negative isolates and our study similar to Bodey et al., who found E. coli, Klebsiella species, and $P$. aeruginosa accounting for the majority of microbiologically documented infections at most cancer centers. The presence of ESBL producing Enterobacteriaceae, carbapenem resistant Enterobacteriaceae and multidrug-resistant A. baumannii is now routinely encountered among cancer patients (Bodey et al., 1966; Arnan et al., 2011; Irfan et al., 2008; Sood et al., 2012). An increase of ESBL producing $E$. coli was observed throughout our study period $40 \%$ in 2008 to $77 \%$ in 2014 study similar to cancer patients by Maria Fernanda Golzarri et al., (2009). Of the infections polymicrobial infection isolates was $516 \quad(33.37 \%)$ and monomicrobial isolates was $386(24.96 \%)$ 
with the gram negative bacilli E.coli and Enterococci species as the main isolates respectively in contrast to the study by Kenneth Rolston et al., (2015) on SSIs in cancer patients where $58 \%$ were monomicrobial and $42 \%$ were polymicrobial and $85 \%$ of the 215 monomicrobial infections were due to gram-positive organisms and $13 \%$ by gram negative bacilli. S.aureus was the predominant pathogen in monomicrobial infections (70\%). Sixty (40\%) of these Staphylococcal isolates were methicillin resistant (MRSA). $P$. aeruginosa was the predominant gram negative pathogen (19 of 27, 70\%).E. coli, Klebsiella and Enterococci species were the predominant gram negative bacilli and gram positive cocci pathogens isolated in polymicrobial infections while $E$. coli was the main isolate in monomicrobial infection (2010), a study on BSSIs had $60 \%$ monomicrobial and $40 \%$ polymicrobial infections.

\begin{tabular}{|l|l|c|}
\hline \multicolumn{3}{|c|}{ Table.1 } \\
Main Bacteriological spectrum out of 1546 Surgical Site Infections \\
\hline Sl. No. & \multicolumn{1}{|c|}{ Name } & Total No. \\
\hline 1. & Gram Negative Bacilli & 1058 \\
\hline 2. & Gram Positive Cocci & 488 \\
\hline 3. & Polymicrobes & 516 \\
\hline 4. & Monomicrobes & 386 \\
\hline 5. & Extended-spectrum $\beta$-lactamases & 400 \\
\hline
\end{tabular}

\begin{tabular}{|c|c|c|c|c|c|c|c|}
\hline \multicolumn{7}{|c|}{ Table.2 Spectrum Of Pathogens Causing Surgical Site Infections } & \multirow[b]{2}{*}{ Citrobacter } \\
\hline $\begin{array}{l}\text { Sl. } \\
\text { No }\end{array}$ & $\begin{array}{l}\text { Gram } \\
\text { Negative } \\
\text { Bacilli } \\
\end{array}$ & E.coli & $\begin{array}{l}\text { Klebsiella } \\
\text { spp. }\end{array}$ & $\begin{array}{l}\text { Pseudomonas } \\
\text { spp. }\end{array}$ & NFGNB & Proteus spp & \\
\hline 1. & & $59.73 \%$ & $13.98 \%$ & $10.39 \%$ & $8.12 \%$ & $5.86 \%$ & $1.89 \%$ \\
\hline 2. & ESßL & $82 \%$ & $8 \%$ & $1.5 \%$ & $4 \%$ & $3 \%$ & $1.5 \%$ \\
\hline & $\begin{array}{l}\text { Gram } \\
\text { Positive } \\
\text { Cocci }\end{array}$ & $\begin{array}{l}\text { Enterococci } \\
\text { Spp }\end{array}$ & S.aureus & MRSA & CONS & B-Streptococci & \\
\hline 3. & & $53.68 \%$ & $41.30 \%$ & $2.86 \%$ & $1.6 \%$ & $0.2 \%$ & \\
\hline
\end{tabular}

E.coli:Escherichia coli; NFGNB:Non Fermenting Gram Negative Bacilli; ES $\beta$ L: Extended Spectrum beta-lactamases; S.aureus:Staphylococcus aureus; MRSA:Methicillin Resistant Staphylococcus aureus; CONS:Coagulase Negative Staphylococcus 


\begin{tabular}{|c|c|c|c|c|c|c|c|c|}
\hline \multicolumn{9}{|c|}{$\begin{array}{c}\text { Table.3 Resistance Pattern Of Gram Negative Bacilli } \\
\text { Total Number } 1058\end{array}$} \\
\hline Pathogen & Amikacin & Cefataxime & Ceftazidime & Cefuroxime & Gentamicin & Ciprofloxacin & Cefaperazone & Imipenem \\
\hline E.coli & $\begin{array}{l}104 \\
(9.82 \%) \\
\end{array}$ & $\begin{array}{c}670 \\
(63.32 \%) \\
\end{array}$ & $\begin{array}{c}428 \\
(40.45 \%) \\
\end{array}$ & $\begin{array}{c}434 \\
(41.02 \%) \\
\end{array}$ & $\begin{array}{c}114 \\
(10.77 \%)\end{array}$ & $\begin{array}{c}322 \\
(30.43 \%) \\
\end{array}$ & $\begin{array}{c}44 \\
(4.15 \%) \\
\end{array}$ & $\begin{array}{c}28 \\
(2.64 \%) \\
\end{array}$ \\
\hline Klebsiella species & $\begin{array}{c}38 \\
(3.59 \%) \\
\end{array}$ & $\begin{array}{c}98 \\
(9.26 \%)\end{array}$ & $\begin{array}{c}82 \\
(7.75 \%)\end{array}$ & $\begin{array}{c}96 \\
(9.07 \%)\end{array}$ & $\begin{array}{c}52 \\
(4.91 \%)\end{array}$ & $\begin{array}{c}70 \\
(6.61 \%)\end{array}$ & $\begin{array}{c}18 \\
(1.70 \%)\end{array}$ & $\begin{array}{c}22 \\
(2.07 \%)\end{array}$ \\
\hline NFGNB* & $\begin{array}{c}30 \\
(2.83 \%)\end{array}$ & $\begin{array}{c}36 \\
(3.40 \%)\end{array}$ & $\begin{array}{c}44 \\
(4.15 \%)\end{array}$ & $\begin{array}{c}56 \\
(5.29 \%)\end{array}$ & $\begin{array}{c}24 \\
(2.26 \%)\end{array}$ & $\begin{array}{c}40 \\
(3.78 \%)\end{array}$ & $\begin{array}{c}10 \\
(0.94 \%)\end{array}$ & $\begin{array}{c}18 \\
(1.70 \%)\end{array}$ \\
\hline Proteus species & $\begin{array}{c}16 \\
(1.51 \%)\end{array}$ & $\begin{array}{c}12 \\
(1.13 \%)\end{array}$ & $\begin{array}{c}26 \\
(2.45 \%)\end{array}$ & $\begin{array}{c}26 \\
(2.45 \%)\end{array}$ & $\begin{array}{c}12 \\
(1.13 \%)\end{array}$ & $\begin{array}{c}10 \\
(0.94 \%)\end{array}$ & $\begin{array}{c}2 \\
(0.18 \%)\end{array}$ & $\begin{array}{c}2 \\
(0.18 \%)\end{array}$ \\
\hline $\begin{array}{l}\text { Pseudomonas } \\
\text { Species }\end{array}$ & $\begin{array}{c}18 \\
(1.70 \%)\end{array}$ & $\begin{array}{c}18 \\
(1.70 \%)\end{array}$ & $\begin{array}{c}8 \\
(0.75 \%)\end{array}$ & $\begin{array}{c}4 \\
(0.37 \%)\end{array}$ & $\begin{array}{c}28 \\
(2.64 \%)\end{array}$ & $\begin{array}{c}20 \\
(1.89 \%)\end{array}$ & $\begin{array}{c}4 \\
(0.37 \%)\end{array}$ & $\begin{array}{c}6 \\
(0.56 \%)\end{array}$ \\
\hline $\begin{array}{l}\text { Citrobacter } \\
\text { species }\end{array}$ & $\begin{array}{c}10 \\
(0.94 \%)\end{array}$ & $\begin{array}{c}16 \\
(1.51 \%)\end{array}$ & $\begin{array}{c}16 \\
(1.51 \%)\end{array}$ & $\begin{array}{l}18 \\
(1.70 \%)\end{array}$ & $\begin{array}{c}6 \\
(0.56 \%)\end{array}$ & $\begin{array}{c}6 \\
(0.56 \%)\end{array}$ & $\begin{array}{c}6 \\
(0.56 \%)\end{array}$ & ----------- \\
\hline
\end{tabular}


Int.J.Curr.Microbiol.App.Sci (2016) 5(10): 605-616

\begin{tabular}{|c|c|c|c|c|c|c|c|}
\hline \multicolumn{8}{|c|}{ Table.4 Resistance Pattern Of Gram Positive Cocci; Total Number 488} \\
\hline Pathogen & Amkacin & Erythromicin & Gentamicin & Cephalexin & Netilmicin & Vancomycin & Rifampicin \\
\hline $\begin{array}{l}\text { Enterococci } \\
\text { Species }\end{array}$ & $\begin{array}{c}40 \\
(8.19 \%)\end{array}$ & $\begin{array}{c}128 \\
(26.2 \%)\end{array}$ & $\begin{array}{c}114 \\
(23.36 \%)\end{array}$ & $\begin{array}{c}42 \\
(8.60 \%)\end{array}$ & ----------- & ------------- & \\
\hline $\begin{array}{l}\text { Staphylococcus } \\
\text { aureus }\end{array}$ & $\begin{array}{c}12 \\
(2.45 \%)\end{array}$ & $\begin{array}{c}62 \\
(12.70 \%)\end{array}$ & $\begin{array}{c}68 \\
(13.93 \%)\end{array}$ & $\begin{array}{c}52 \\
(10.65 \%)\end{array}$ & $\begin{array}{c}2 \\
(0.40 \%)\end{array}$ & $\begin{array}{c}4 \\
(0.81 \%)\end{array}$ & $\begin{array}{c}6 \\
(1.22 \%)\end{array}$ \\
\hline MRSA* & $\begin{array}{c}4 \\
(0.81 \%)\end{array}$ & $\begin{array}{c}4 \\
(0.81 \%)\end{array}$ & $\begin{array}{c}6 \\
(1.22 \%)\end{array}$ & $\begin{array}{c}10 \\
(2.04 \%)\end{array}$ & ----------- & ------------ & $\begin{array}{l}2 \\
(0.40 \%)\end{array}$ \\
\hline CONS** & --------- & $\begin{array}{c}4 \\
(0.81 \%)\end{array}$ & ------------ & $\begin{array}{c}4 \\
(0.81 \%)\end{array}$ & --------- & --------- & ------------ \\
\hline
\end{tabular}

*MRSA - Methicillin Resistant Staphylococcus aureus.

**CONS - Coagulase Negative Staphylococcus. 
Methicillin Resistant Staphylococci aureus (MRSA) isolation in our study was low $(0.20 \%)$ which co-relate to the study of Maria Fernanda Golzarri in a study of 1863 SSIs for over a period of 6 years. And to the contrary of study by Roy Chemaly who report increase in incidence of MRSA in their study of SSIs in cancer patients. Kenneth et al., (2010) report a sixty (40\%) isolation of MRSA from a study of 368 surgical site infections in cancer patients.

Study on surgical site bacterial infections at the national cancer institute in mexico: A case-control study by Diana Vilar-Compte, found most frequently isolated pathogen were E. coli 38 (21.8\%), Pseudomonas sp 22 (12.6\%), S. aureus $16 \quad(9.2 \%)$, and coagulase-negative $S$ taphylococci 25 $(13.6 \%)$ and infer that the surgical site infection rate in cancer hospital is slightly higher than the rates reported for general hospitals which is contrary to the BSSI's from our cancer hospital. Unhealing surgical site infections will be prone towards longer mean hospital stay, multiply drug resistance, probabality of burst abdomen due to sepsis, and wound dehiscence. Surgical site infections protocol for patients with febrile and afebrile neutropenia may have to to be implemented to reduce morbidity and motality of the patients. Risk factors such as age, immunocompromised state, diabetes, duration of surgery, time of drain in - situ depending on the organ site may play a major role in BSSI's.

Diana Vilar-Compte, et al., in their study found diabetes mellitus, obesity, and prolonged presence of a surgical drain as risk factors for SSI's. Wheras Jelena et al., found age, sex, BMI, history of smoking and underlying diabetes were not associated with risk factors for their SSI's. H.Tominaga (2007) suggest that age, tumor site, operating time, amount of bleeding and SSI risk index were all important SSIs risk factors in predicting colorectal cancer surgery.

Diana et al., (2009) established concomitant preoperative chemoradiation, haematoma, age $\geq$ 58years,body mass index $\geq 30.8$ and duration of surgery $\geq 160$ minutes were found to be SSI-associated risk factors and emphasize the need to identify SSIassociated risk factors and improve quality of care to patients.

Our study involved all onco surgical services in our hospital and respective surgical risk factors were not done due to unavailability of many data. In our study we isolated E.coli and Enterococci as the predominant gram negative bacilli and gram positive cocci respectively as the main onco SSI bacterial pathogen.

In conclusion, despite suppressed immune status in cancer patients, infections and associated various risk factors, BSSIs is low in our hospital. To have a "no BSSI's" in a cancer hospital inadvertent overuse of higher antibiotics must be avoided to reduce multiply drug resistance, implementation of institutional antibiotic policy to oncosurgical patients, evaluation of inherent oncosurgical risk factors pre, peri and post operatively need to be defined and incorporated.

\section{References}

Anaya, D.A., Cormier, J.N., Xing, Y., Koller, P., Gaido, L., Hadfield, D., et al. 2012. Development And validation of a novel stratification tool for identifying cancer patients at increased risk of surgical site infection. Ann. Surg., 255(1): 134-9.

Arnan, M. et al. 2011. Risk factors for, and clinical relevance of, faecal extended- 
spectrum beta-lactamase producing Escherichia coli (ESBL-EC) carriage in neutropenic patients with haematological malignancies. Eur. J. Clin. Microbiol. Infect. Dis., 30: 355360.

Asfia, S., Meher, R., Fatima, K., Sana, A., Indu, S., Abida, K. 2015. Incidence of surgical site infections, their etiology, associated antimicrobial use and antimicrobial resistance I a tertiary care centre in northern india. Euro. $J$. Pharma and Med. Res., 2: 347-352.

Ashley, B., Catalina, E., Karen, B., Alasdair, M., John, R.W. 2000. The passage of bacteria through surgical drapes. Ann. R. Coll. Surg. Engl., 82: 405-407.

Bodey, G.P., Buckley, M., Sathe, Y.S., Freireich, E.J. 1966. Quantitative relationships between circulating leukocytes and infection in patients with acute leukemia. Ann. Intern. Med., 64: 328-340.

Chemaly, R.F., Hachem, R.Y., Husni, R.N., Bahna, B., Rjaili, G.A., Waked, A. et al. 2010. Characteristics and outcomes of methicillin-resistant staphylococcus aureus surgical-site infections in patients with cancer: A case-control study. Annals of Surg. Oncol., 17: 1499-1506.

Clinical and Standards for Antimicrobial and Laboratory Standards Institute (CLSI). 2011. Performance Standards for Antimicrobial Susceptibility Testing, Twenty-first Informational Supplement M 100-S21. Wayne, PA:CLSI.

Collee, J.G., Miles, R.S., Watt, B. 1996. Tests for identification of bacteria. In: Collee, G., Marmion, B.P., Fraser, A.G., Simmons, A., editors. Mackie and McCartney Practical Medical Microbiology. New York:Churchhill Livingstone, 131-49.

Diana Vilar-Compte, Sameul, R., Norma,
H.M., Eduardo, M., Patricia, V. 2009. Surveillance, Control and Prevention of SSI in breast cancer surgery: a 5 year experience. Amer. J. Infect. Control, 37: 674-679.

DianaVilar-Compte, Alejandro, M., Silvia, S., Margarita de la Rosa, Patricia, G., Patricia, V. 2000. Surgical site infections at the National Cancer Institute in Mexico: A case-control study. Amer. J. Infect. Control, 28: 1420.

Eduardo, V.L.C., Carlos Alberto de Souza, M., Leda Maria de Castro, Vania Maria da, C.G. 1998. Risk index for prediction of surgical site infection after oncology operations. Amer. J. Infection Control, 26: 217-223.

Elting, L.S., Bodey, G.P., Fainstein, V. 1986. Polymicrobial septicemia in the cancer patient. Med., 65: 218-2 25.

Gudiol, C. et al. 2010. Bacteraemia due to extended-spectrum beta-lactamaseproducing Escherichia coli (ESBLEC) in cancer patients: clinical features, risk factors, molecular epidemiology and outcome. $J$. Antimicrob. Chemother., 65: 333-341.

Horan, T.C., Gaynes, R.P., Martone, W.J., Jarvis, W.R., Emori, T.G. 1992. CDC definitions of nosocomial surgical site infections, 1992: a modification of CDC definitions of surgical wound infections. Infect Control Hosp. Epidemiol., 13: 606-608.

Irfan, S. et al. 2008. Emergence of Carbapenem resistant Gram negative and vancomycin resistant Gram positive organisms in bacteremic isolates of febrile neutropenic patients: a descriptive study. BMC Infect. Dis., 8: 80 .

Jeffrey, J.T., Kenneth, V.R. 2003. Current Spectrum of Bacterial Infections in Patients with Cancer. Clin. Infect. Dis., 37: 1144-1145. 
Jelena Sotirović, Vesna Šuljagić , Nenad Baletić, Ljubomir Pavićevi, Milan Erdoglija, Aleksandar Perić and Ivan Soldatović. 2015. Factors for Surgical Site Infection in Laryngeal Cancer Surgery. Acta Clin. Croat, 54: 57-64.

Jelena, S., Vesna, Š., Nenad, B., Ljubomir, P., Dušan, B., Milan, Aleksandar, P., Ivan, S. 2015. Risk factors for surgical site infection in laryngeal cancer surgery. Acta Clin. Croat, 4: 57-64.

Kenneth, V.I.R., Lior, N., Jeffrey, T.T. 2014. Current Microbiology of Surgical Site Infections in Patients with Cancer: A Retrospective Review. Infect. Dis. Ther., 3: 245-256.

Kunz, A.N., Brook, I. 2010. Emerging resistant Gram-negative aerobic bacilli in hospital acquired infections. Chemother., 56: 492-500.

Law, W.L., Chu, K.W. 2004. Anterior resection for rectal cancer with mesorectal excision: a Prospective evaluation of 622 patients. Ann. Surg., 240: 260- 268.

Mahdi, H., Gojayev, A., Buechel, M., Knight, J., SanMarco, J., Lockhart, D., Michener, C., Moslemi-Kebria, M. 2014. Surgical site infection in women undergoing surgery for gynecologic cancer. Int. J. Gynecol. Cancer, 24: 779-786.

Mangram, A.J., Horan, T.C., Pearson, M.L., Silver, L.C., Jarvis, W.R. 1999. Guideline for prevention of surgical site infection, Hospital Infection Control Practices Advisory Committee. Infect. Control Hosp. Epidemiol., 20: 250-278.

Maria, F.G., Juan Carlos Hernaiz-Leonardo, Mauricio, O., Consuelo VelazquezAcosta, Patricia Cornejo- Juarez, Diana Vilar-Compte. 2015. Microbiology of Surgical Site Infections in Cancer Patients: A Seven Year Review. Open Forum Infect.
Dis., 2: 71-536.

Meuid, M.M., Denobis, D., Meguid, V. 1988. Complication of abdominal operations for malignant disease. Am. J. Surg., 156: 341-345.

Montes, C.V., Vilar-Compte, D., Velazquez, C., Golzarri, M.F., Cornejo-Juarez, P., Larson, E.L. 2014. Risk factors for extended spectrum $\beta$-lactamaseproducing Escherichia coli versus susceptible E. coli in surgical site infections among cancer patients in Mexico. Surg. Infect, (Larchmt), 15: 627-634.

Nikolaos, V.S., Gerald, P.B., Dimitrios, P.K. 2005. Perspectives for the Management of Febrile.Neutropenic Patients with Cancer in the 21st Century. Cancer, 1103.

Ortega, M. et al. 2009. Analysis of 4758 Escherichia coli bacteraemia episodes: predictive factors for isolation of an antibiotic-resistant strain and their impact on the outcome. J. Antimicrob. Chemother., 63: 568-574.

Owens, C.D., Stoessel, K. 2008. Surgical site infections: epidemiology, microbiology and prevention. J. Hosp. Infect., 70 Suppl 2: 3-10.

Paulo, T.O.C., Andre, L.C., Stela, V.P., Milene, M., Afonso, D.C.P. 2011. Surgical-site infection risk in oncologic digestive surgery. Braz. $J$. Infect. Dis., 15: 109-115.

Peter, C., Nowell. 2003. Management of Health-Care-Associated Infections in the Oncology Patient. Cancer Network Home J. Oncol., 1-8.

Serra-Aracil, X., García-Domingo, M.I., Parés, D., Espin-Basany, E., Biondo, S., Guirao, X., Orrego, C., SitgesSerra, A. 2011. Surgical site infection in elective operations for colorectal cancer after the application of preventive measures. Arch. Surg., 146: 606-12. 
Sood, P. et al. 2012. Emergence of multidrug resistant acinetobacter blood streaminfections in febrile neutropenia patients with haematological cancers and bone marrow failure syndromes. J. Indian Med. Assoc., 110: 439-444.

Sutton, S.H. 2014. Infections associated with solid malignancies. Cancer Treat Res., 161: 371-411.

Teresa, R.Z. 2014. Epidemiology of infections in cancer patients. Infectious Complications. In Cancer. Patients, Cancer Treatment and Research Springer International Publishing Switzerland, 43-89.

Tominaga, H., Koseki, M., Hatanaka, N., Miyamoto, K., Kamiike, W. 2007. Surgical Site Infection in Colorectal Cancer. Amer. J. Hosp. Infec., 35: 188-189.
Tsuyoshi, K., Toshiaki, W., Junji, K., M.A., Hirokazu, N. 2006. Elective Colon and Rectal Surgery Differ in Risk Factors for Wound Infection Results of Prospective surveillance. Ann. Surg., 244: 758- 763.

Velasco, E., Thuler, L.C., Martins, C.A., et al. 1998. Risk index for prediction of surgical site infection after oncology operations. Am. J. Infect. Control, 26(3): 217-223.

Velasco, F., Thuler, L., Martins, C.A., et al. 1997. Nosocomial infection in an oncology intensive care unit. Am. $J$. Infect. Control, 26: 458-462.

Vigil, K.J. et al. 2009. Multidrug-resistant Escherichia coli bacteremia in cancer patients. Amer. J. Infect. Control, 37: 741-745.

\section{How to cite this article:}

Sumathi, B.G. 2016. Bacterial Pathogens of Surgical Site Infections in Cancer Patients at a Tertiary Regional Cancer Centre, South India. Int.J.Curr.Microbiol.App.Sci. 5(10): 605-616. doi: http://dx.doi.org/10.20546/ijcmas.2016.510.068 